\title{
Climate Change and Energy Management Strategies
}

\author{
Elshan Moradkhani \\ Engineering Faculty, Karaj Azad University, Karaj, Iran \\ Email: elshan.moradkhani12@gmail.com
}

How to cite this paper: Moradkhani, E. (2017) Climate Change and Energy Management Strategies. Computational Water, Energy, and Environmental Engineering, 6, 143-153.

https://doi.org/10.4236/cweee.2017.62011

Received: February 8, 2017

Accepted: March 5, 2017

Published: March 8, 2017

Copyright $\odot 2017$ by author and Scientific Research Publishing Inc. This work is licensed under the Creative Commons Attribution International License (CC BY 4.0).

http://creativecommons.org/licenses/by/4.0/

\section{(c) (i) Open Access}

\begin{abstract}
Current climate challenges and energy concerns have urged scientists, researchers, and governments to take action in order to reduce carbon footprint and energy consumption. Considering the growing need for energy supplies, the reliability and sustainability of power plants are another area of concern for communities. Since building is among the major consumers of electricity (almost 40\%), the energy management strategies have been substantially focused on demand side management and building operation system. Energy efficiency, peak-load management, and demand response are among the most outstanding and widespread practices in order to reduce building energy consumption and peak demand. Smart grids and smart meters are considerably gaining the attention of policy makers in most developed and developing countries. This paper will revolve around these outstanding energy management strategies and technologies and their merits and drawbacks in the journey of current communities towards sustainability.
\end{abstract}

\section{Keywords}

Smart Meters, Electricity Rate, Smart Grids, Climate Change,

Peak Load Management

\section{Introduction}

Since the Kyoto protocol in 1997 [1] identified global warming as a major issue and recognized anthropomorphic $\mathrm{CO}_{2}$ as the major contributor, focus has been directed to reduce or eliminate these emissions in order to alleviate climate concerns. A rise in greenhouse Gas (GHG) emissions began with the industrial revolution 250 years ago. Unfortunately, there are increasing releases of GHGs as technology progresses and demand for energy is expanding due to developing economies such as China and India [2]. For example, total primary energy requirement (PER) in China increased from 570 to 3200 Mtce (Megaton of coal 
equivalent) from 1978 to 2010 for an annual average growth rate of $5.6 \%$ per year [3]. This number is estimated to increase up to 6200 Mtce by 2050, while more than $70 \%$ of this energy is thought to be supplied by fossil fuels, introducing more $\mathrm{CO}_{2}$ to the environment. This increasing trend has urged scientist to take action and to apply and create more energy efficient technologies, detect any potential area to increase efficiency in existing systems, and most importantly to identify and target end users consuming highest amount of energy.

Energy crisis is a broad issue that needs governmental action as well as social engagement. Climate change and society are inseparable; human contribution in climate change is undeniable, on the other hand, climate change increasingly affects human welfare. However, researches have shown that societal and individual engagement in global warming mitigation and their knowledge and motivation to do so is extremely limited. Public awareness is not merely enough to press the illness, private individuals need behavioral engagement; people need to understand the cause and consequences of carbon emissions, and should be given the ability to reduce their carbon emission in their everyday life or, in other word, need to be "carbon capable" [4]. Social and lifestyle changes should be addressed all over the communities; governments, industries, commercial sectors, academia, and individuals.

Although social awareness and climate concerns are getting widespread, there are some structural, economic, and social barriers hindering societal engagement [5]. Smart grids and smart buildings have capabilities to create opportunities for consumers to engage in low-carbon lifestyle. They enable policymakers to specify tariffs in a way that they could motivate consumers to cooperate with smart grids and enable both smart grids and consumers to integrate local or centralized renewable energy sources into the electricity network.

The ramification of global changes is not limited to direct effects on human welfare and future life on the planet. It does have some indirect impacts that are less emphasized when referring to global warming. The growing population and developing technologies surprisingly increase demand for energy supplies. Although power plants expansion is inevitable, the commitments to climate change mitigation tends to decrease $\mathrm{CO}_{2}$ emissions. During peak hours, when electricity demand is maximum, power plants are more distressed to provide electricity for their growing customers. Power outage may occur that is one of the most outstanding indirect impacts of climate change on people's life. Power outage could even happen because of the extreme weather, resulting from human activities, damaging power infrastructures specifically transmission lines. To prevent power outage, while avoiding power plants expansion, communities need either to utilize alternative energy sources like renewable energies or energy storage systems or to reduce consumptions especially during peak hours. Intermittent renewable energy sources are not yet efficient and reliable enough to control energy market. Expensive infrastructures and retrofits are required before RESs extensive implementation. Energy storage, if available, could provide heat or cold for limited hours a day. Energy management and demand response, how- 
ever, are long-term, reliable solutions for current energy and climatic crisis. The economic and technical barriers in replacing fossil-fueled power plants with RESs shed light on the significance of energy-efficiency, demand reduction, and low-carbon activities. In order for communities to reduce their carbon emissions and mitigate climate change, to increase overall sustainability and stability, and to decrease climate change impact on human being a stable and reliable power system is required; Smart grids.

It is simplistic to assume that the stability that smart grids may create would not require human intervention and their societal and behavioral adjustment. Smart network include smart buildings and smart users. People, in average, spend more than $90 \%$ of their time inside buildings and this dependence makes buildings and human inseparable. One of the greatest building services in HVAC system that is one the largest energy consumers inside building. When Demand Response (DR) occurs in a smart building (manually or automatically) the temporary reduction in building services (lighting level, heating, cooling, and ventilation,) would affect building occupants negatively and would compromise their thermal comfort resulting from a reduction in HAVC services during peak hours. Consumer's motivations to cooperate with smart grid (their concerns for environment, their own and offspring's health and safety, or their budget) or even their denial to cooperate would have an impact on their expectations and behavioral adjustment. The current paper elaborates on different measures and strategies that have been introduced to alleviate climate concerns and manage energy consumption and build power network sustainability as well as their merits and drawbacks [6].

\section{Energy Management}

Buildings have been major contributors in current energy crisis and climate challenges. N. Motegi in his paper discusses the different measures that are common in building industry to manage energy consumption, utility bills, and greenhouse gases emissions. Energy efficiency and conservation that mean lowering energy consumption without affecting building services and reduction in unnecessary energy consumption respectively are among the most important practices. These measures are possible through installing energy efficient equipment and operating building efficiently through manipulating building automation systems (BAS) and control systems. Industrial energy management, since industries consume a substantial amount of energy each day is another growing area of research and development. Industrial refrigerators are other major consumers of electricity. Novel technologies, however, try to replace fossil fuels with renewable energies and recover waste heat to reduce energy consumption. In [7], an industrial, ammonia-water absorption refrigeration system that consumes solar or geothermal energy or power plants waste heat as energy supply is analyzed and cooling effect (down to $233 \mathrm{~K}$ ) is studied with $12 \%$ higher efficiency relative to similar fossil-fueled system. In another paper she compares this system with a conventional fossil fueled system and a $6 \%$ increase in COP was 
shown through recovering waste heat in expander [8].

Second practice is peak load management, which includes demand limiting (discharging loads during a pre-defined peak demand) and demand shifting (changing the time of electricity consumption). These practices can be achieved through energy storage systems installation (like cold or heat storage) or by postponing practices like laundry or dish washing to later times like late at night when energy consumption is relatively lower.

The third practice, demand response (DR) shares the same concept with peakload management; however, DR initiates in response to high electricity price or high demand and grid limited capacity and it takes benefit of real-time pricing and grid reliability data while there is no pre-determined peak-demand. In [9], $\mathrm{DR}$ is defined as "dynamic and event-driven that can be a short-term modification in costumer end-use electric loads in response to dynamic prices and reliability information". DR will be more discussed in following paragraphs. Figure 1 depicts and compares the demand saving potential of energy efficiency and demand limiting, shedding, and shifting [9].

\section{Smart Grids and Smart Meters}

\subsection{Definitions}

Since information and communication technology (ICT) has given rise to the concept of smart grids and smart meters, the challenge of integrating end users with the grid and maximizing this communication network capabilities in terms of saving energy, demand, and the environment has been under spotlight. The word "smart" is a broad context and when it refers to building or energy system it translates to something that is equipped with advanced technologies and control system, enabling different things to communicate with each other within the network and efficiently respond to internal and external signals. Based on this definition, smart grid is the modernized and revolutionary regime of existing

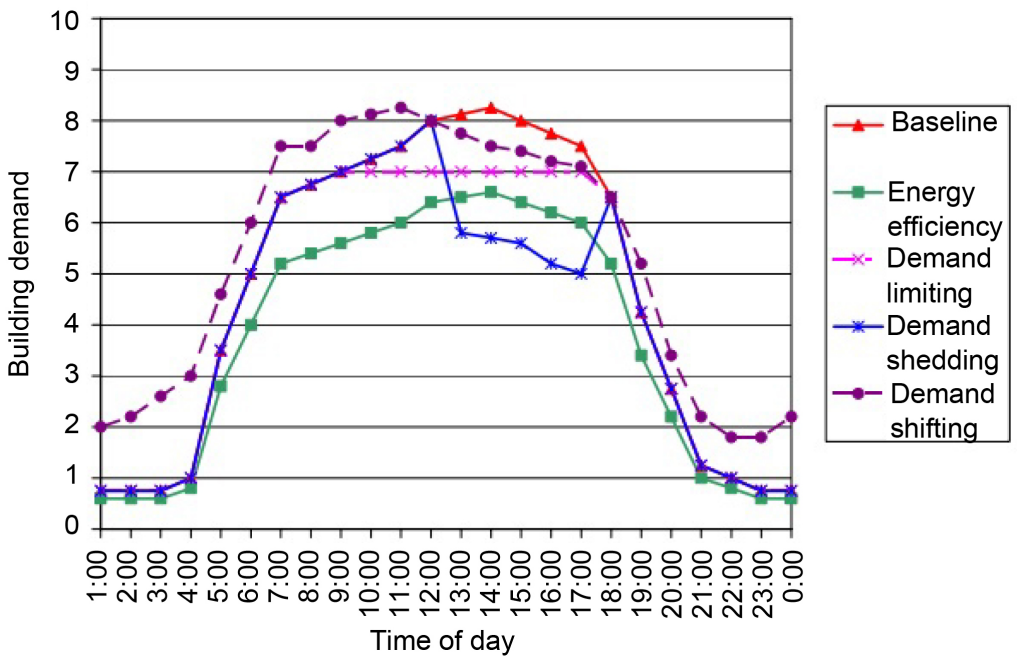

Figure 1. Examples of load shapes, this chart is conceptual; the data are not from actual measurements [9]. 
electrical grid that is equipped with information and communication technology to efficiently produce, transmit, and distribute electricity. Its interaction with smart meters within the network improves grid sustainability and stability. Patrick McDaniel defines smart grid as "a network of computers and power infrastructures that monitor and manage energy usage" [10].

Smart meter system is a bidirectional communication device between smart meter and smart grid that includes smart meter, communication tools, and control devices. Smart meters can read and record real-time consumption data from consumer's premises and securely communicate data. These devices send feedback to power grids and enable them to have secure access to consumption data. Moreover, they enable consumers to receive real-time data including real-time prices and to adjust their consumption pattern. Smart meters are programmable and are equipped with sensors, enabling them to control appliances and other electric devices, turn them off and on when needed, control maximum consumption, and so on. Additionally, smart meter is capable of distinguishing among different power sources and based on the source type (customer-owned energy storage devices or renewable sources, decentralized sources, or power grids) it provides billing information. Smart meters can also communicate with each other if accessible, compete with neighbors in reducing energy consumption, and provide electricity from locale producers if available. The schematic below depicts the differences between manual and smart meters [9] [11].

Buildings consume approximately $40 \%$ of total energy consumption in developed countries and almost half of this energy (20\%) associates with HVAC system, providing building occupant's with acceptable thermal comfort. Assuming this large amount of energy dedicated to buildings and occupant's thermal comfort, it is almost impossible to have a sustainable community lacking green, smart, and sustainable buildings and HVAC systems integrated to the smart energy network [12]. Smart buildings, through involving in Demand Response (DR) programs could contribute to electricity network sustainability in the community; however, engineers and facility managers should be aware of the ramification of this cooperation on building occupants, specifically their thermal comfort. Since HVAC systems are the major end-users of electricity they have a substantial potential to integrate with DR events. Figure 1 shows a conceptual load distribution during day time.

\subsection{Smart Grid Vulnerability}

Developed countries such as Germany, UK, US, Canada, and Australia are committed to install smart meters in households in order to manage peak demand and GHG emissions and to increase electricity network security and reliability [13]. Other capabilities are integrating renewable energy sources and even local retailers and electricity producers (prosumers) into the smart grids, smart meters, and associated communication technology. However, some drawbacks are limiting consumer's interest and increasing concern over widespread implementation of smart meters. First, installation, replacement, and maintenance of 
smart meters require billion dollars to be invested. Moreover, there should exist a robust network for all interconnected components and electrical devices (The internet of things) to communicate with each other. This is a sizable challenge for utility companies as well; they need to adjust with ongoing technology and make choices available for customers to cooperate with smart grids [9]. The replacement and maintenance expenses can be decrease by using newly developed SHM methods which replace the scheduled-based maintenance with as-needed maintenance. Guided wave based SHM methods are among these methods which has been extensively researched using different methods such as WSFE-based UEL [14] [15] [16] and the peridynamics [17] [18]. The climate change has some practical implications which limit the predictability of the energy generation. As an example, this fact is more emphasized when using wind turbine energy [19] [20].

Network systems, rather than demanding a substantial investment for deployment and maintenance, they are prone to malicious cyber and terrorist attack, theft, consumer's misuse of other's data, etc. Smart meters could possibly reveal household's consumption data while communication, data that carry information about occupant's absence or presence at home. Therefore, smart meter struggle with considerable privacy and security challenges while collecting and transmitting data that needs to be eliminated before gaining widespread applications (even though they are already broadly implemented in many countries especially in Europe). Recent efforts revealed that even existing countermeasure techniques do not eliminate vulnerability issues. It is worth to mention that both power grids and buildings have been prone to cyber-attack even before their interconnection in the form of the internet of things. However, due to the increased points of entries in a heterogeneous network with interconnected devices and their different capabilities, and because of distributed, multi-agent control system in contrast with the hierarchical control system in conventional networks, it is complicated to provide a strong and uniform protection for the entire smart network [9] [11]. Figure 2 provides a comparison between conventional and smart methods of energy metering.

Conventional Energy Meter

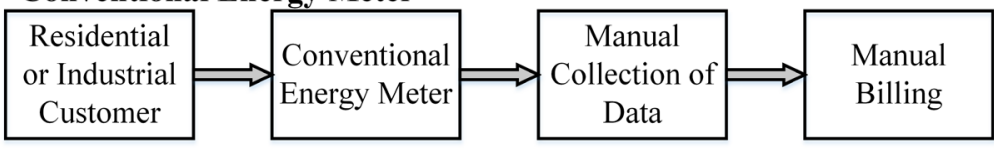

Smart Meter System

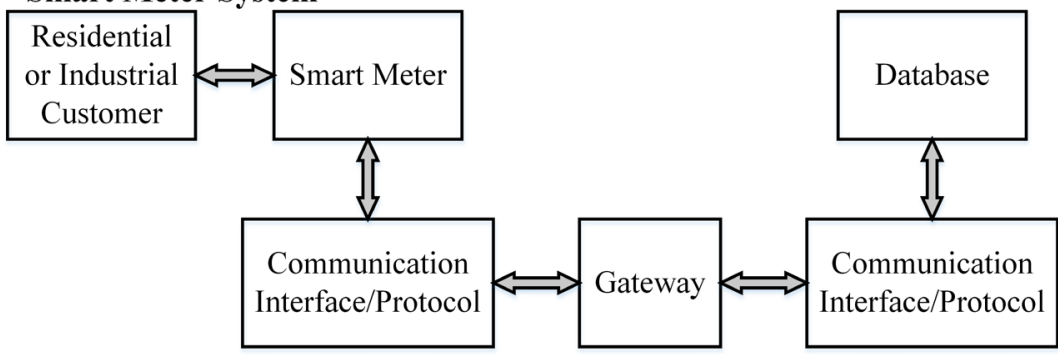

Figure 2. Conventional vs. smart meters [9]. 
Data storage and transition is another notable challenge for smart meters. Since the storage capacity is always limited, it is important to identify important data to store and the storage time period. Data transition that usually occurs through low bandwidth brings about a heavy traffic making data storage and transition capacity so limited. However, the advantages smart meters offer to the power grids and to their customers outweighs its drawbacks and with lots of engineers and researchers struggling hard to improve the existing prototypes and minimize their deficiencies a brighter future for smart meters in power grids is yet to come.

Nowadays, with an increasing demand to develop a sustainable community, building a reliable energy network is critical since the foundation of a sustainable community lays on a sustainable energy system. A sustainable energy system is the one that allows for interactions between various energy sources, domestic, decentralized, or centralized, renewable, or conventional energy systems. A robust energy system through manipulating GIS (Geographic Information System) is capable of fault detection and could pin point the location of inefficient devices, enabling energy network to prevent losses. A smart meter is a device that helps customers to monitor consumption data for each appliance, control power quality and peak demand, and/or shut the electricity down when consumers exceed the maximum consumption threshold. A smart grid that could distinguish between electricity coming from power grids and those coming from thermal storage or renewable sources could help utility companies in billing their customers based on the real-time data. Soma Shekara [12] in his paper encourages developed countries to replace their conventional power networks with smart grids to overcome their sustainability and peak demand challenges.

\section{Dynamic and Time-Dependent Electricity Rate}

At the beginning of 20th century, California encountered a severe electricity capacity shortage in a part resulting from inappropriate link between wholesale and retail market and lack of engagement in real-time demand response by retail market. Since then, both in California and across the United States the energy policy shifted towards enhancing real-time demand response to the dynamic electricity pricing through a robust real-time link between wholesale and retail market in residential and commercial sectors. The Energy Policy Act of 2005 urges all the facilities and technologies nationwide to be available for electricity customers enabling them to participate in demand response practices and to adjust themselves with volatile, real time electricity pricing system [21] [22].

Direct Load Control (DLC) program and Time of Use (TOU) tariffs are being applied for years in residential building as two major tariffs in order to reduce peak demand. DLC programs offers billing credits in exchange of large endusers consumption control and management. This program is usually active during summer and its major targets are central HVAC systems. A major practice of DLC is increasing thermostat setpoint up to usually $4^{\circ} \mathrm{F}$ or turning HVAC systems on and off in varying increments during hot summer days. DLC is easy for 
customers to apply it with existing technologies, however, it is not a time-based practice and it cannot be helpful during special events and emergency times [21] [22].

TOU or time of use program allocates higher electricity prices for weekday afternoons. Therefore, a constant time dependent schedule helps power system reliability through decreasing peak-hours consumption and shifting usage to the off-peak hours. However, it does not support a dynamic, real-time, and event driven tariff applicable to emergencies when power system works near or with full capacity [21] [22].

Although TOU tariffs have been successful in improving power grids reliability and demand reduction, their participation in on-peak reduction is typically around 5\%. The tendency for considerable peak-demand reduction in North America and securing grids reliability especially on event driven basis has drawn attentions towards dynamic pricing such as Critical Peak Pricing (CPP) and Real Time Pricing program (RTP) program [21] [22].

CPP shares the same principal as TOU tariffs; however, these tariffs are applied only to limited special events where high demand is predicted in advance. Real-Time price, however, mirrors real-time production cost of electricity in the market. Thus, the electricity rate varies hourly and price vs. time of the day profile changes on a daily basis. The electricity price in not known until approximately twenty four to one hour beforehand and in contrast to above mentioned tariffs there is no predetermined $\$ / \mathrm{kW}$ available. RTP have been considerably successful in saving demand and money in large commercial and industrial firms, nevertheless, RTP implementation is so confusing and troublesome for small households so that it is not usually applied for household applications, instead, CPP is a more common measure for residential purposes [21] [22] [23].

Research has shown that occupant's response to CPP varies depending on buildings, customers, and climate characteristics. This discussion is out of the scope of this paper and references purposes [21] [22] [23] provide more details in this regard.

\section{Demand Response}

\subsection{Definitions}

"Demand response (DR) is a set of time dependent program activities and tariffs that seek to reduce electricity use or shift the usage to another time period" [9]; in other words DR is a set of consumers actions, either voluntarily or impulsively, in order to flatten the demand profile, reduce consumption during peak hours, and enhance grid security and reliability. Demand response enables control system that is linked with a smart grid to reduce or delay electricity consumption in peak hours. Since peak-demand is coupled with peak pricing, demand response would help consumers in decreasing their electricity bills (cost reduction) and would contribute to a more reliable and sustainable electric grid [24]. Demand response has a similar policy to energy efficiency, however, whenever demand response does not affect building services and occupant's comfort 
it should be considered a "permanent energy efficiency opportunity". Unlike energy efficiency measures, that are part of normal building operation, DR has dynamic characteristics and takes place in response to smart grid signals as a temporary reduction in service. These signals are in form of phone calls, text messages, or emails for manual and semi-automated DR and in the form of direct signals from smart grids to equipment and control system in fully automated DR. DR is applicable both manually and automatically or as a mixture of two that is called semi-automated DR.

\subsection{HVAC-Based Demand Response}

In cooling seasons when outside air temperature goes up, the demand for HVAC systems is maximum and this is synchronized with maximum electric rate (peak hours). A demand response program is capable to reduce energy consumption, utility bills, and peak demand at peak hours. In [9], the primary goal of HVACbased DR is discussed to minimize peak demand while minimizing negative effects of building occupants. He proposes that there are two major strategies to meet these goals: "Global temperature adjustment of zones, or systematic adjustment to the air distribution system and/or cooling system", while the first strategy better guarantees DR goals. Each building differs in DR strategies depending on building design and application, climate condition, mechanical equipment, building automation system, and building control and energy management policies. It is impossible to precisely predict the DR saving potential due to its correlation with dynamic outside air pattern and unpredictable energy demand [9].

\section{References}

[1] Grubb, M., Vrolijk, C. and Brack, D. (1997) The Kyoto Protocol: A Guide and Assessment. Royal Institute of International Affairs, London.

[2] Govindaraju, V.C. and Tang, C.F. (2013) The Dynamic Links Between $\mathrm{CO}_{2}$ Emissions, Economic Growth and Coal Consumption in China and India. Applied Energy, 104, 310-318. https://doi.org/10.1016/j.apenergy.2012.10.042

[3] Yang, L., Yan, H. and Lam, J.C. (2014) Thermal Comfort and Building Energy Consumption Implications-A Review. Applied Energy, 115, 164-173.

https://doi.org/10.1016/j.apenergy.2013.10.062

[4] Whitmarsh, L., O’Neill, S., Seyfang, G. and Lorenzoni, I. (2009) Carbon Capability: What Does It Mean, How Prevalent Is It, and How Can We Promote It. Tyndall Centre for Climate Change Research, Norwich.

[5] Semenza, J.C., Hall, D.E., Wilson, D.J., Bontempo, B.D., Sailor, D.J. and George, L.A. (2008) Public Perception of Climate Change: Voluntary Mitigation and Barriers to Behavior Change. American Journal of Preventive Medicine, 35, 479-487. https://doi.org/10.1016/j.amepre.2008.08.020

[6] Murakami, S., Levine, M.D., Yoshino, H., Inoue, T., Ikaga, T., Shimoda, Y. and Fujisaki, W. (2007) Energy Consumption and Mitigation Technologies of the Building Sector in Japan. 6th International Conference on Indoor Air Quality, Ventilation \& Energy Conservation in Buildings, Sendai, 28-31 October 2007.

[7] Aghniaey, S. and Mahmoudi, S.M.S. (2014) Exergy Analysis of a Novel Absorption 
Refrigeration Cycle with Expander and Compressor. Indian Journal of Scientific Research, 1, 815-822.

[8] Aghniaey, S. and Mahmoudi, S.M.S. (2014) A Comparison between the Novel Absorption Refrigeration Cycle and the Conventional Ammonia-Water Absorption Refrigeration Cycle. International Conference on Heat Transfer, Fluid Mechanics and Thermodynamics, Florida, 14-16 July 2014.

[9] Motegi, N., Piette, M.A., Watson, D.S., Kiliccote, S. and Xu, P. (2007) Introduction to Commercial Building Control Strategies and Techniques for Demand Response. LBNL-59975, Lawrence Berkeley National Laboratory, Berkeley. https://doi.org/10.2172/1004169

[10] McDaniel, P. and McLaughlin, S. (2009) Security and Privacy Challenges in the Smart Grid. IEEE Security \& Privacy, 7, 75-77. https://doi.org/10.1109/MSP.2009.76

[11] Liu, Y., Ning, P. and Reiter, M.K. (2011) False Data Injection Attacks against State Estimation in Electric Power Grids. ACM Transactions on Information and System Security, 14, 13. https://doi.org/10.1145/1952982.1952995

[12] DoE, U.S. (2011) Buildings Energy Data Book. Energy Efficiency and Renewable Energy Department, Washington DC.

[13] Strengers, Y. (2011) Air-Conditioning Australian Households: The Impact of Dynamic Peak Pricing. Energy Policy, 38, 7312-7322. https://doi.org/10.1016/j.enpol.2010.08.006

[14] Khalili, A., Samaratunga, D., Jha, R., Lacy, T.E. and Gopalakrishnan, S. (2015) Wavelet Spectral Finite Element Based User-Defined Element in Abaqus for Modeling Delamination in Composite Beams. 23rd AIAA/ASME/AHS Adaptive Structures Conference, Kissimmee, Kissimmee, 5-9 January 2015. https://doi.org/10.2514/6.2015-1726

[15] Khalili, A., Jha, R. and Samaratunga, D. (2017) The Wavelet Spectral Finite ElementBased User-Defined Element in Abaqus for Wave Propagation in One-Dimensional Composite Structures. Simulation: Transactions of the Society for Modeling and Simulation International. https://doi.org/10.1177/0037549716687377

[16] Khalili, A., Jha, R. and Samaratunga, D. (2016) Spectrally Formulated User-Defined Element in Conventional Finite Element Environment for Wave Motion Analysis in 2-D Composite Structures. European Journal of Computational Mechanics, 25, 446474.

[17] Amin, Y. and Chorzepa, M.G. (2015) Meshless Modeling Framework for Fiber Reinforced Concrete Structures. Computers \& Structures, 161, 43-54. https://doi.org/10.1016/j.compstruc.2015.08.015

[18] Amin, Y. and Chorzepa, M.G. (2017) Fracture Analysis of Fiber Reinforced Concrete Structures in the Micropolar Peridynamic Analysis Framework. Engineering Fracture Mechanics, 169, 238-250. https://doi.org/10.1016/j.engfracmech.2016.11.004

[19] Gharghabi, P., Dordizadeh, P. and Niayesh, K. (2015) Impact of Metal Thickness and Field Shaper on the Time-Varying Processes during Impulse Electromagnetic Forming in Tubular Geometries. Journal of the Korean Physical Society, 59, 35603566.

[20] Gharghabi, P., Lee, J., Mazzola, M. and Lacy, T. (2016) Development of an Experimental Setup to Analyze Carbon/Epoxy Composite Subjected to Current Impulses. Proceedings of the American Society for Composites, Williamsburg, 9-21 September 2016.

[21] Depuru, S.S.S.R., Wang, L. and Devabhaktuni, V. (2011) Smart Meters for Power 
Grid: Challenges, Issues, Advantages and Status. Renewable and Sustainable Energy Reviews, 15, 2736-2742. https://doi.org/10.1016/j.rser.2011.02.039

[22] Herter, K. and Wayland, S. (2010) Residential Response to Critical-Peak Pricing of Electricity: California Evidence. Energy, 35, 1561-1567.

https://doi.org/10.1016/j.energy.2009.07.022

[23] Herter, K. (2010) Residential Implementation of Critical-Peak Pricing of Electricity. Energy Policy, 35, 2121-2130. https://doi.org/10.1016/j.enpol.2006.06.019

[24] Newsham, G.R. and Bowker, B.G. (2010) The Effect of Utility Time-Varying Pricing and Load Control Strategies on Residential Summer Peak Electricity Use: A Review. Energy Policy, 38, 3289-3296. https://doi.org/10.1016/j.enpol.2010.01.027

Submit or recommend next manuscript to SCIRP and we will provide best service for you:

Accepting pre-submission inquiries through Email, Facebook, LinkedIn, Twitter, etc. A wide selection of journals (inclusive of 9 subjects, more than 200 journals) Providing 24-hour high-quality service User-friendly online submission system Fair and swift peer-review system Efficient typesetting and proofreading procedure Display of the result of downloads and visits, as well as the number of cited articles Maximum dissemination of your research work

Submit your manuscript at: http://papersubmission.scirp.org/

Or contact cweee@scirp.org 